\title{
Percepção da enfermagem sobre condições de trabalho em unidades de saúde da família na Paraíba - Brasil
}

\author{
Nursing's perception regarding the work conditions at family health units in João Pessoa, Paraíba, Brazil
}

Percepción de Enfermería acerca de condiciones laborales en unidad de salud de la familia en Paraíba

Cleyton Cézar Souto Silva ${ }^{1}$, Lígia Maria Cabedo Rodrigues² ${ }^{2}$ Vívian Karla Bezerra Alves da Silva ${ }^{3}$, Ana Cristina de Oliveira e Silva ${ }^{4}$, Vera Lúcia do Amaral e Silva ${ }^{5}$, Marcelle de Oliveira Martins ${ }^{6}$

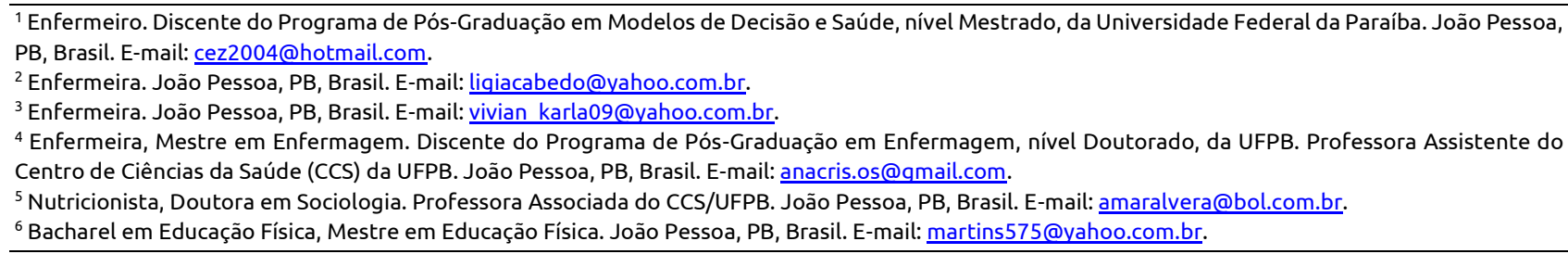

\section{RESUMO}

O presente trabalho trata-se de estudo descritivo, com abordagem qualitativa, que objetivou descrever e caracterizar as percepções dos profissionais de Enfermagem acerca dos acidentes e condições de trabalho das Unidades de Saúde da Família de João Pessoa-PB. A coleta deu-se entre outubro e dezembro de 2010, por meio de entrevista semiestruturada (com doze trabalhadores) e análise de conteúdo (modalidade temática). Foram encontradas quatro categorias temáticas: Acidentes de trabalho (com a palavra o trabalhador de Enfermagem); Riscos de acidentes inerentes ao trabalho na Unidade de Saúde da Família; A saúde do trabalhador na atenção primária; Promoção da saúde do trabalhador e prevenção de acidentes de trabalho na Unidade de Saúde da Família. Conclui-se que há uma adequada percepção dos profissionais sobre o tema, mesmo estando submetidos a condiçães de trabalho insalubres com sobrecarga de trabalho e falta de infraestrutura e de equipamentos de proteção.

Descritores: Programa Saúde da Família; Acidentes de Trabalho; Enfermagem do Trabalho; Saúde do Trabalhador.

\section{ABSTRACT}

The objective of this descriptive, qualitative study present study was to describe and characterize nursing professionals' perceptions regarding occupational accidents and the working conditions at Family Health Units in João Pessoa, Paraíba, Brazil. Data collection took place between October and December of 2010, through semi-structured interviews (with twelve workers) and content analysis (thematic). Four thematic categories were found: Occupational accidents (associated with the work nursing worker); Accident risks inherent to working at the Family Health Unit; The health of primary health care workers; The health promotion of workers and preventing occupational accidents at the Family Health Unit. In conclusion, the workers have an adequate perception regarding the theme, despite being subjected to unhealthy working conditions dealing with an overload of work and a lack of infrastructure and protective equipment.

Descriptors: Family Health Program; Accidents, Occupational; Occupational Health Nursing; Occupational Health.

\section{RESUMEN}

Estudio descriptivo de abordaje cualitativo, objetivando describir y caracterizar las percepciones de los profesionales de Enfermería acerca de accidentes y condiciones laborales de las Unidades de Salud de la Familia de João Pessoa-PB. Datos recolectados de octubre a diciembre de 2010, mediante entrevista semiestructurada (12 trabajadores) y análisis de contenido, modalidad temático. Fueron encontradas cuatro categorías temáticas: Accidentes de trabajo: tiene la palabra el trabajador de Enfermería; Riesgos de accidentes inherentes al trabajo en Unidad de Salud de la Familia; Salud del trabajador en atención primaria; Promoción de salud del trabajador y prevención de accidentes de trabajo en Unidad de Salud de la Familia. Se concluye en que hay una adecuada percepción profesional sobre el tema, incluso estando sometidos a condiciones de trabajo insalubres, con sobrecarga laboral e infraestructura y equipamientos de protección insuficientes.

Descriptores: Programa de Salud Familiar; Accidentes de Trabajo; Enfermería del Trabajo; Salud Laboral. 


\section{INTRODUÇÃO}

Os acidentes de trabalho (AT) são agravos que, pelo seu expressivo impacto na morbimortalidade da população, constituem-se em um importante problema de saúde pública sendo, portanto, objeto prioritário das ações do Sistema Único de Saúde (SUS) que em conjunto com outros setores dos serviços públicos e da sociedade civil, como os sindicatos, as Delegacias Regionais do Trabalho e o Instituto Nacional de Previdência Social, devem continuar a buscar formas efetivas para o seu enfrentamento(1).

Conceitua-se como AT o evento súbito ocorrido no exercício de atividade laboral, independentemente da situação empregatícia e previdenciária do trabalhador acidentado, que acarreta dano potencial ou imediato à saúde, provocando lesão corporal ou perturbação funcional que causa direta ou indiretamente a morte, perda ou redução, permanente ou temporária, da capacidade para o trabalho. Inclui-se ainda o acidente ocorrido em qualquer situação em que o trabalhador esteja representando os interesses da empresa ou agindo em defesa de seu patrimônio, assim como aquele ocorrido no trajeto da residência para o trabalho ou vice-versa ${ }^{(1)}$.

Há três modalidades de AT: o acidente típico, decorrente da característica da atividade profissional desempenhada pelo acidentado; o acidente de trajeto, ocorrido no caminho entre a residência e o local de trabalho e vice-versa; e as doenças profissionais ou do trabalho, adquiridas ou desencadeadas em função de condições especiais em que o trabalho é realizado e que se relacionem diretamente com ele ${ }^{(2)}$. Todos acometem anualmente um grande número de trabalhadores e, conforme sua gravidade, provoca sequelas temporárias ou permanentes, quando não levam ao óbito(3).

Essa problemática é revelada pelos dados da Previdência Social(4) que, nos anos de 2000 a 2009, registraram na Paraíba 12.960 AT, sendo 6.819 classificados como típicos, 1.315 acidentes de trajeto e 631 doenças do trabalho. Já os dados do Sistema de Informação de Agravos de Notificação (SINAN), disponibilizados em 2011 pelo Centro de Referência em Saúde do Trabalhador (CEREST), regional de João Pessoa (JP), informam que no período de 2007 a 2010, em JP ocorreram 308 notificações de AT: 144 casos resultaram em incapacidade laboral temporária, 13 em incapacidade parcial permanente, quatro em incapacidade total permanente e 21 em mortes por acidentes fatais. Ocorreram ainda na capital 270 acidentes com material biológico e 92 lesões por esforço repetitivo/doenças osteomusculares relacionadas ao trabalho (LER/DORT).

A Estratégia Saúde da Família (ESF), enquanto maneira de reorientar o modelo assistencial do Sistema Único de Saúde (SUS), constitui-se em um importante mercado de trabalho para os profissionais de enfermagem no país. A atuação da enfermagem na ESF vem consolidando-se na prática e na experiência adquirida pelos profissionais de saúde na saúde coletiva, construindo ao longo dos últimos anos o SUS ${ }^{(5)}$.

Refletindo especificamente sobre a temática da saúde do trabalhador de Enfermagem, percebe-se que estas discussões ainda estão em fase inicial, necessitando-se mais estudos que analisem os riscos a que estes profissionais encontram-se expostos, para assim possibilitar a construção de novas e melhores políticas para os trabalhadores de saúde e segurança para os profissionais desta área.

Acredita-se que na área da saúde, a equipe de enfermagem é uma das principais categorias ocupacionais sujeita à exposição por material biológico. $O$ trabalhador de enfermagem atua num ambiente às vezes penoso e insalubre que não oferece condições favoráveis para sua saúde e satisfação pessoal. A precarização do trabalho, seja pelo excesso de atividade laboral física e mental, acúmulo de horas trabalhadas, sistema de vínculo empregatício, ou mesmo má remuneração ocupacional no sistema de saúde, é determinante dos acidentes e doenças ocupacionais ${ }^{(6)}$.

Um estudo realizado em unidades de saúde de Cuiabá, Mato Grosso(7), mostrou que os AT foram abordados em várias pesquisas envolvendo os trabalhadores da saúde atuantes em instituições hospitalares.

No entanto, poucos estudos relatam sobre os acidentes de trabalho ocorridos nos serviços da Atenção Primária em Saúde. Embora uma pesquisa feita com 21 equipes de saúde da família no município de Ceará-Mirim, no Rio Grande do Norte ${ }^{(8)}$, tenha identificado que os profissionais atuavam em um cenário laboral inadequado com indisponibilidade de equipamentos e instrumentos, além de insuficiência financeira e instabilidade do vínculo trabalhista que podem favorecer a ocorrência de tal agravo. 
Outro estudo realizado no interior do Rio de Janeiro $^{(9)}$, concluiu em seus resultados que o enfermeiro que atua na ESF não conhece em sua totalidade os riscos ocupacionais, assim como as estratégias apontadas por eles para a minimização destes não são eficazes para a execução de um trabalho seguro.

Diante disto, percebe-se a importância e a necessidade de investigar esta realidade, e propõe-se como objetivo principal descrever e caracterizar as percepções dos profissionais de Enfermagem acerca dos acidentes e condições de trabalho em Unidades de Saúde da Família (USF) de João Pessoa/PB.

\section{METODOLOGIA}

Este é um estudo descritivo com abordagem qualitativa, parte de um projeto maior intitulado "Riscos ocupacionais e acidentes de trabalho entre os profissionais de Enfermagem de Unidade de Saúde da Família" aprovado pelo Comitê de Ética em Pesquisa do Hospital Universitário Lauro Wanderley com protocolo de número 531/10.

A coleta foi realizada de outubro a dezembro de 2010, em quatro Unidades de Saúde da Família (USF) na cidade de João Pessoa/PB. A escolha das Unidades deveuse ao fato de que as mesmas configuraram-se como campos de atuação dos enfermeiros da Residência Multiprofissional em Saúde da Família e Comunidade (RMSFC) da Universidade Federal da Paraíba (UFPB), e acreditou-se que assim fosse possível tornar a entrevista mais fidedigna devido à relação de vinculo pré-existente com os trabalhadores destas USF, o que permite confirmação dos dados fornecidos bem como uma possível relação de confiança para proferir os discursos necessários à coleta de dados.

Os sujeitos pesquisados foram 12 profissionais de Enfermagem que se dispuseram a participar da pesquisa e assinaram o Termo de Consentimento Livre e Esclarecido (seis enfermeiros e seis técnicos de Enfermagem), do total de 23 trabalhadores de Enfermagem das referidas USF, tendo sido observados, como critérios de inclusão: ser profissional de Enfermagem e atuar em USF há mais de um ano.

Utilizou-se entrevista semiestruturada que tiveram como questões norteadoras para este estudo: O que você entende por acidente de trabalho? Diante de um acidente de trabalho na USF que condutas você adotaria? Na sua opinião, quais as principais causas dos acidentes de trabalho, em se tratando de profissionais de Enfermagem que atuam em USF?

As entrevistas foram realizadas em ambiente privativo, nas dependências das USF, uma pessoa por vez. Foram gravadas em Mp4 player sendo transcritas na íntegra, e o tratamento dos dados seguiu os princípios da análise temática de conteúdo ${ }^{(10)}$, com operacionalização pelos seguintes passos: a) ordenação dos dados; b) classificação; e c) análise final. Esse procedimento permitiu ordenar o conjunto dos dados, com classificação preliminar para apreender as estruturas de relevância (temas emergentes dos discursos, constituindo as categorias de análise) e com agrupamento dos núcleos de sentido mais recorrentes (discursos com mesmo assunto ou argumento, dentro de cada categoria) para proceder à análise final (interpretação dos dados).

Foi solicitada ao Departamento de Atenção em Saúde (Secretaria Municipal de Saúde de João Pessoa) autorização para a realização da pesquisa nas USF, e atendida a Resolução 196/96 do Conselho Nacional de Saúde que trata das pesquisas envolvendo seres humanos $^{(11)}$. Para identificação dos discursos cada sujeito foi identificado por letra maiúscula, seguida de algarismo arábico (total de seis enfermeiros = E1 a E6; total de seis técnicos de Enfermagem = T1 a T6).

\section{RESULTADOS E DISCUSSÃO}

Os 12 profissionais entrevistados (11 mulheres e um homem) tinham idade entre 24 a 62 anos e atuações na Estratégia Saúde da Família (ESF) variando de um até 12 anos de trabalho. Foram reconhecidas quatro categorias temáticas e correspondentes subcategorias representadas na Figura 1: 
Figura 1: Plano de análise com categorias temáticas. João Pessoa, PB.

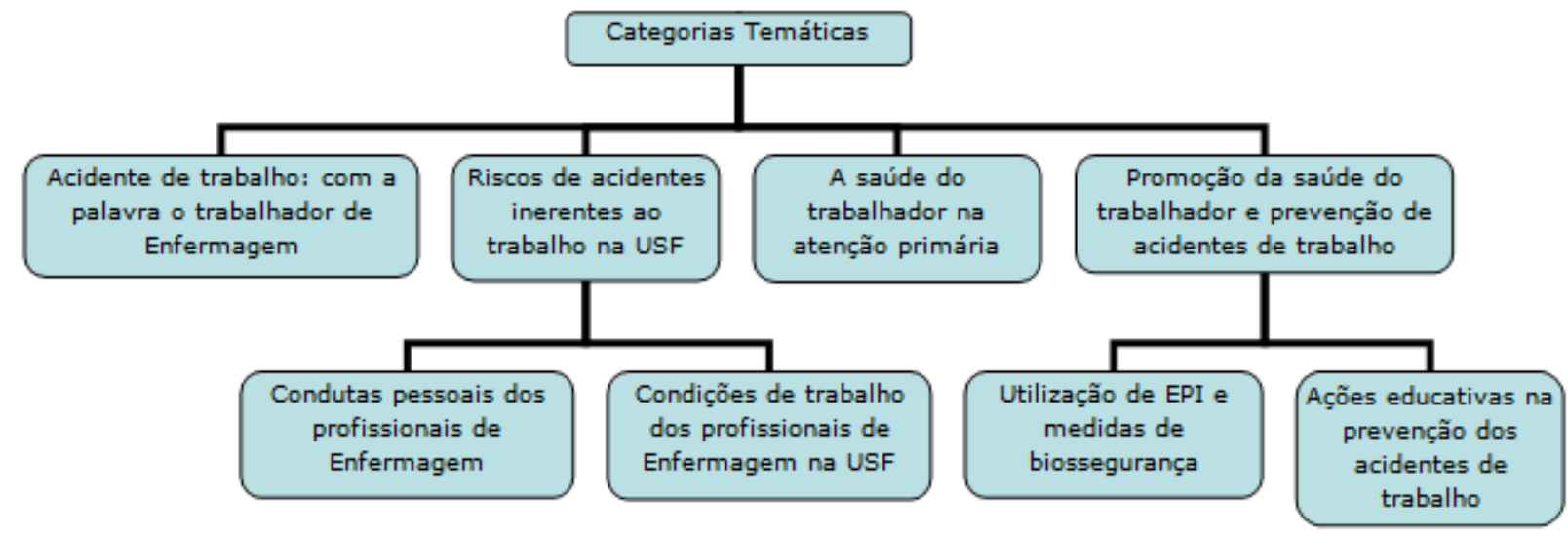

\section{Acidentes de trabalho: com a palavra o trabalhador de Enfermagem}

Os depoimentos possibilitaram a compreensão da percepção particular dos trabalhadores de Enfermagem sobre o conceito de AT, expresso por seu conhecimento teórico, bem como pela prática laboral e por casos que aconteceram na USF.

Os acidentes nas instituições de saúde podem estar relacionados a uma série de fatores predisponentes devido às peculiaridades das atividades realizadas na assistência ao ser humano. Dentre esses fatores estão os físicos, químicos, biológicos, psicossociais e ergonômicos. São considerados como material biológico, o sangue e fluidos orgânicos (sêmen, secreção vaginal, líquor, líquidos sinovial, pleural, peritoneal, pericárdico e amniótico), sendo potencialmente contaminantes ${ }^{(12)}$.

Os entrevistados demonstram em seus relatos possuírem entendimento adequado sobre AT em diversas modalidades, relacionando-os ao exercício do trabalho. Ressalta-se que muitos relatos trouxeram exemplos de casos que ocorreram no próprio espaço de trabalho:

Acidente de trabalho... eu penso assim, que é qualquer processo que interrompa o desenvolvimento da atividade laboral, seja física, psicológica (E5).

Principalmente quando leva a um adoecimento pelo trabalho (E3).

Todo e qualquer acidente ocorrido na prática profissional... uma queda no chão ou num piso molhado, um acidente com perfuro-cortante, uma agressão física ou verbal (E4).

Eu lembro que espirrou um pouco da secreção no citológico, e teve contato com meus olhos, com a mucosa (E6).
Minha colega colheu sangue e quando colocou no tubo ele explodiu. E isso já aconteceu comigo também, o sangue bateu no meu rosto, no meu olho (T5).

Aconteceu um acidente aqui na sala de vacina, de fazer uma injeção e a agulha saiu e furou o profissional (T3).

Já aconteceu de uma técnica de Enfermagem ficar em uma sala sem ventilação... teve que subir numa bancada para abrir uma janela e se desequilibrou e caiu (T6).

É desde quando você sai de casa... você vindo de casa até o trabalho e sofrer algo é um acidente (T1).

O trabalho no setor saúde, por exemplo, é executado em locais onde existe constante exposição a fatores de risco de diversas ordens, que prejudicam aqueles que ali exercem atividades laborais. Entre os muitos agravos que acometem a saúde dos profissionais deste setor, os AT sobrevêm de maneira abrupta ou insidiosa no corpo dos trabalhadores, em decorrência do desgaste sofrido e provocado pela exposição às cargas de trabalho existentes nos processos de trabalho dos serviços de saúde ${ }^{(13)}$.

Equiparam-se também ao AT o acidente sofrido pelo trabalhador no local e no horário do trabalho, decorrente de ato de agressão, ofensa física intencional ou imprudência de terceiros ${ }^{(9)}$, tendo sido citado neste estudo ("agressão física ou verbal", por E4), e que implica em situações de estresse que favorecem acidentes. De fato, o desgaste a que as pessoas são submetidas, nos ambientes e nas relações com o trabalho, é um dos fatores na determinação das doenças dos mais significativos ${ }^{(14)}$.

Já os ferimentos com agulhas e material perfurocortante, em geral, são considerados extremamente 
perigosos por serem potencialmente capazes de transmitir mais de 20 tipos de patógenos, como o vírus da imunodeficiência humana (HIV), o da hepatite B e o da hepatite $C$, os agentes infecciosos mais comumente envolvidos em $A T^{(15)}$. Em estudo realizado pelo CERESTLondrina mostrou-se que os serviços de saúde que mais registraram AT com exposição biológica foram as Unidades Básicas de Saúde (UBS), seguidas do Centro Cirúrgico, Pronto-socorro e Enfermarias ${ }^{(14)}$.

Em todo caso, a equipe de Enfermagem é uma das principais categorias profissionais sujeitas às exposições com material biológico. Este fato relaciona-se à Enfermagem ser a profissão da área da saúde a ter mais contato direto na assistência aos pacientes e também ao tipo e à frequência de procedimentos realizados ${ }^{(15)}$, o que também é comprovado pelos discursos apresentados nesta subcategoria. É importante considerar que saber definir ou entender o que é AT pode ser um dos primeiros passos para reconhecê-lo e, diante disto, evitá-lo ou minimizá-lo.

\section{Riscos de acidentes inerentes ao trabalho na USF}

Nesta categoria foi apresentada a percepção dos trabalhadores sobre as possíveis causas dos AT no ambiente de trabalho. Verificou-se que eles atribuem causas a atitudes pessoais ou às condições do trabalho.

Todavia, considera-se que cada uma das posições descritas filia-se a uma determinada corrente analítica que tem referencial teórico particular, as quais influenciam as concepções sobre as causas dos AT, a exemplo da concepção de culpabilidade do trabalhador pelo acidente e/ou adoecimento pelo trabalho.

\section{Condutas pessoais dos profissionais de Enfermagem}

Alguns depoimentos apontam que o AT pode decorrer de condutas pessoais por descuido, falta de conhecimento do profissional ou negligência, como é demonstrado a seguir:

Olha eu acho que é a falta de precaução do profissional porque ele sabe como evitar... Muitas vezes a gente pensa que só vai acontecer com o outro... Tem muita gente que pensa assim, aí não se previne, não usa o que é pra ser usado, o EPI, e aí vem os problemas e acidentes em geral (E6).
Acontecem eu acho por causa de uma técnica de trabalho inadequada, que pode acontecer um acidente de trabalho (E2).

Mas isso acontece não porque o material é ruim, mas por falta de conhecimento mesmo... é até a maneira como você tá manuseando o material, às vezes até um descuido também (T5).

Eu fui pegar o material contaminado, o descartex, ai fui mexendo e a agulha me furou lá dentro (T2).

Com efeito, entre os fatores que oportunizam a ocorrência dos AT dentre profissionais de saúde, encontramos descrito na literatura circunstâncias como: o não seguimento às normas de precaução padrão, a ausência de equipamentos de proteção individual (EPI), falta de treinamento, cansaço, repetitividade de tarefas, dupla jornada de trabalho, distúrbios emocionais, excesso de autoconfiança, qualificação profissional inadequada, falta de organização do serviço, desequilíbrio emocional em situações de emergência, negligência de terceiros, carga de tarefas, além das possíveis falhas humanas que podem, porventura, ocorrer durante a execução de procedimentos $^{(2)}$.

Todos estes riscos, contudo, deveriam ser contundentemente evitados. Ressalta-se que o conhecimento técnico, em si, não assegura a adoção de comportamentos seguros no trabalho. Devemos considerar que o próprio processo de trabalho, da maneira alienadora como tem sido empregado atualmente, é o maior responsável pelos AT, sendo o trabalhador o elo mais fraco e aquele que sofre os maiores danos neste processo ${ }^{(16)}$.

Entretanto, aspectos relacionados à mudança de comportamento, bem como estimular a autopromoção da saúde podem contribuir para mudar o panorama de acidentes ocupacionais com material biológico, entre os trabalhadores da área da saúde. Assim, torna-se premente a revisão das estratégias utilizadas nos programas de educação permanente (EP) de modo que estes sejam capazes de contribuir para a conscientização dos profissionais sobre os riscos ocupacionais e, em consequência, valorizarem sua segurança durante o exercício profissional(17). A garantia de ambientes de trabalho seguros, com equipamentos de proteção coletiva de acidentes (EPC) e processos de trabalho seguros para os trabalhadores seriam medidas que 
minimizariam os riscos quando aliadas às medidas proporcionadas pela EP.

A Política Nacional de Educação Permanente em Saúde entendida com "aprendizagem no trabalho, onde o aprender e o ensinar se incorporam ao cotidiano das organizações e ao trabalho", deve ocorrer no cotidiano laboral mediante a análise dos problemas e desafios diários dos trabalhadores. Neste âmbito, o enfermeiro enquanto trabalhador inserido na realidade de uma comunidade deve utilizar esta proposta para transformação das práticas profissionais e da organização do trabalho, recomendando que a educação dos trabalhadores se dê a partir da problematização do processo de trabalho(9).

Condições de trabalho dos profissionais de Enfermagem na USF

O processo de trabalho em saúde pode ser muitas vezes um processo com muitas tensões e organizado de forma a possibilitar a precariedade das condições de trabalho e a sua sobrecarga, o que contribui para aumento das estatísticas de AT neste setor. Há também referência na literatura à redução da atenção ao trabalho e desequilíbrio físico e emocional em decorrência do processo de trabalho tornando os profissionais de Enfermagem mais vulneráveis à ocorrência de $A T^{(18)}$. Os profissionais de Enfermagem, ao longo de sua atuação profissional, tendem a aceitar certas situações de risco como inerentes à profissão. Muitas vezes, submetem-se a trabalhar em condições desumanas, como a falta de recursos humanos e materiais, a sobrecarga de trabalho, relações interpessoais/profissionais conflitantes e outras condições que podem colocá-los frente a várias situações de risco, vulnerabilidade e incapacidade ${ }^{(19)}$.

Os relatos dos entrevistados confirmam tais afirmações, destacando-se a alta demanda, infraestrutura inadequada, falta de EPI, e o estresse que já pode ser caracterizado como um adoecimento no trabalho:

Acho que são causa de acidentes principalmente da falta de equipamentos de proteção individual, o espaço físico inadequados, pouca iluminação (E3).

A unidade ser tão imprensada de equipamentos, sem espaço para os profissionais se locomoverem a ponto de sofrerem acidentes (E5).
A estrutura física inadequada da unidade, porque tem ambientes que fica impossivel você estar trabalhando no calor (E4).

Porque às vezes não tem luva, falta material. A gente sentia pena do usuário e fazia curativo sem pinça, sem luva, sem proteger as mãos (T1).

Eu acho que também pode ser o estresse, muita gente pra atender e você naquele corre-corre querendo ser rápida. Pelo menos aqui na USF o número é muito grande de paciente, tem muitas metas para eu fazer, são muitas atribuições (T4).

O excesso de trabalho talvez seja a indicação mais precisa do desequilíbrio entre o trabalhador e o ambiente no qual trabalha o que, associado ao ritmo do trabalho intenso, interfere na qualidade da assistência, nas relações com colegas e contribui para o desgaste físico e emocional do trabalhador ${ }^{(14)}$. Na área de saúde pode-se inferir que a elevação do número de acidentes não ocorre somente em função do maior manuseio de materiais perfurocortantes, mas também pela repetição das ações e o volume de trabalho, o que leva a processos de trabalho falhos e em muitos casos expondo o trabalhador a riscos desnecessários ${ }^{(2)}$. O profissional que realiza mais de uma tarefa ao mesmo tempo, estará mais exposto a acidentes devido ao fato de que, ao realizar o trabalho desta forma, o profissional não estará atento aos próprios limites humanos para executar qualquer tarefa - já que este acúmulo de tarefas exige mais esforço do que o normal, considerando aqui limites tanto físicos quanto fisiológicos, ou mentais e emocionais ${ }^{(20)}$.

\section{A Saúde do Trabalhador na Atenção Primária}

Os profissionais entrevistados entendem a importância da notificação do acidente e até conhecem os instrumentos para isso, apesar da ausência destes no serviço. Com relação ao fluxo de assistência ao trabalhador acidentado dentro da rede de saúde do município, alguns relatos são opostos quanto a afirmar ou não que conhecem os encaminhamentos que devem ser tomados.

No Brasil, a notificação compulsória é o principal instrumento para o conhecimento de acidentes e doenças relacionadas ao trabalho, explicitando as causas pelas quais os trabalhadores adoecem ou morrem. Nesta perspectiva, a notificação compulsória da ocorrência de 
acidentes de trabalho permite reconhecer a gravidade destes acidentes e é uma ferramenta ímpar no delineamento de estratégias de prevenção e controle de agravos à saúde do trabalhador ${ }^{(17)}$.

Na perspectiva de oferecer assistência integral ao trabalhador o MS criou, em 2002, através da Portaria n. 1.679, uma Rede Nacional de Atenção Integral à Saúde do Trabalhador (RENAST)(21), tendo como uma das estratégias para sua estruturação a organização e implantação de uma rede de serviços de saúde ambulatoriais de média e alta complexidade, responsáveis por diagnosticar os acidentes e doenças relacionadas ao trabalho e por registrá-los no SINAN, e que responda pela execução de ações curativas, preventivas, de promoção e de reabilitação da Saúde do Trabalhador(18).

Os relatos evidenciam a percepção da importância da notificação para a saúde do trabalhador, e refletem a fragilidade na implementação da política de saúde do trabalhador. É importante notar também que alguns trabalhadores que sofreram AT não informaram o acontecido, nem procuraram assistência especializada, como se observa nos depoimentos:

Eu acredito [sobre a conduta a ser adotada] seria ter que notificar o acidente de trabalho. Formalizar o acidente, eu nunca tive essa prática não (E4).

O perfuro-cortante, a gente tem que preencher a ficha de notificação de acidente de trabalho (CAT), deveria ter em todos os locais de trabalho e aqui a gente não tem (E1).

Notificar. Mas ainda não foi elaborado um instrumento mesmo para deixar na unidade pra gente tá fazendo uma notificação dessa (E6).

Eu sei que existe uma linha de cuidado de saúde do trabalhador, na teoria, existe todo um protocolo, fichas de preenchimento de acidente de trabalho, onde se encaminhar. Não existe na verdade aqui na atenção básica (E2).

Eu não procurei o caminho correto de fazer toda aquele procedimento de ir lá na unidade de referência para perfuro-cortante (E6).

Eu sei que em primeiro lugar tem que comunicar à minha enfermeira, depois procurar um local pra fazer o exame pra ver se a gente foi contaminado por várias doenças como hepatite e AIDS (T2).
Quando eu me cortei eu procurei um hospital que é a referência especializada, fiz o exame (T5).

Não conheço não, o fluxo dentro da rede de saúde (T1).

$\mathrm{Na}$ verdade a gente não tem nenhuma orientação em relação a acidente. A gente procura resolver dentro da própria unidade com nossos gestores, nossos apoiadores, através da equipe (E3).

No Brasil, os CEREST mantêm o registro sistematizado dos Acidentes de Trabalho através do SINAN atendendo a portaria $n^{\circ} 144 / 2011$ do Ministério da Saúde (MS)(22). Espera-se que com essa estratégia seja possível identificar, controlar e minimizar os índices de AT no país. No entanto, é essencial que os profissionais de saúde tenham consciência da importância da notificação do AT, prática que embora seja legalmente exigida, não é efetuada por muitos serviços de saúde ${ }^{(22)}$.

Existe um elevado índice de subnotificação dos AT porque as vítimas consideram 0 acidente sem importância, ou porque o material tinha sido utilizado em pessoas que eles julgam conhecidos, ou ainda pelo desconhecimento referente ao dever de comunicar o acidente. Estas atitudes impedem que tenhamos noção da verdadeira dimensão do problema, fazendo com que ações de prevenção e controle dos acidentes sejam de difícil planejamento e desenvolvimento(23). No presente estudo, verificou-se que esta realidade faz-se presente também em João Pessoa.

\section{Promoção da Saúde do Trabalhador e prevenção de acidentes de trabalho}

Nos depoimentos desta categoria observou-se interrelação entre o uso de EPI, esclarecimento e cuidado (atenção). Muito também foi relatado sobre a falta de capacitações e qualificações sobre biossegurança por parte dos gestores.

Utilização de EPI e medidas de biossegurança

Diversos discursos mostram que os sujeitos reconhecem que o uso correto do EPI diminuiria os acidentes, de maneira que fica difícil identificar se ocorre mesmo o uso regular do equipamento. Sabe-se que o EPI é direito de qualquer trabalhador, mas não deve servir de medida paliativa para mascarar uma condição inapropriada de trabalho. Os seguintes relatos foram destacados: 
Para evitar os acidentes eu posso fazer a utilização dos materiais de proteção que o serviço oferece e que tem que ter para cada procedimento (E3).

\section{É me paramentando (E4).}

Me vigiar mais, tomar os devidos cuidados, tentar se proteger, usar o equipamento para cada procedimento que for feito (T6).

É fazer a limpeza das mãos de um procedimento para outro pra não levar contaminação (T1).

Assim eu procuro me cuidar, embora às vezes nem use o material, mas eu procuro ter cuidado (T3).

No Brasil, foi instituída em 2005 uma Norma Regulamentadora, a NR-32(24), que estabelece as diretrizes básicas para a aplicação de medidas de proteção à segurança e à saúde dos trabalhadores dos serviços de saúde, com a finalidade de melhorar as condições laborais nesses setores e minimizar os vários problemas ocupacionais existentes ${ }^{(17)}$. Segundo esta norma é dever do serviço fornecer o EPI em quantidade e qualidade cabendo ao trabalhador utilizá-lo apenas com a finalidade a que se destina, responsabilizar-se por sua guarda e conservação, além de comunicar ao empregador qualquer dano ou alteração que o torne impróprio para o uso(16). $^{(16)}$

Entretanto, mesmo com a disponibilidade desses equipamentos nos locais de trabalho, muitos trabalhadores não utilizam os EPIs, por diversos fatores. Dentre eles destaca-se o desconforto ou incômodo, descuido, esquecimento, falta de hábito ou disciplina, inadequação do equipamento, quantidade insuficiente do mesmo e a não utilização por achar desnecessário(17). Observa-se também que na divisão das tarefas no trabalho da equipe de Enfermagem, sem que haja um rodízio desta divisão, há a mecanização do trabalho, o que, além de atribuir ao processo de trabalho um caráter alienador, contribui para que os profissionais, julgando-se aptos para aquele serviço, executem-no sem tomar medidas adequadas de prevenção de acidentes ${ }^{(20)}$.

Contudo, o emprego de práticas seguras e o uso de equipamentos de proteção adequados reduzem significativamente o risco de acidente ocupacional, fazendo-se necessária também a conscientização dos profissionais para utilização de técnicas assépticas e o estabelecimento de normas de conduta e procedimentos que garantam ao profissional e ao usuário um tratamento sem risco de contaminação(15).

Ações educativas na prevenção dos acidentes de trabalho

Nos depoimentos obtidos visualizamos a importância da contribuição dos próprios profissionais, mesmo que minimamente, através da educação permanente, orientando os demais profissionais da ESF e compartilhando o saber em uma atitude de trabalho em equipe e interdisciplinaridade:

Não é falta de informação, mas o que eu poderia fazer são as palestras educativas relembrando os riscos, mostrando o EPI que tem que se utilizar para evitar esses acidentes (E1). Eu estar orientando os profissionais a tomarem cuidado, a usar equipamentos de segurança (E4).

É uma coisa que tento fazer tanto com os estudantes quanto profissionais, estar próxima tentando orientar o que fazer para não se expor (E6).

Basicamente a gente ter mais cuidado e o pessoal fazer muito treinamento porque o que faz diminuir isso [o AT] é a capacitação (T2).

A educação continuada ou permanente nos serviços de saúde são apontadas como incentivo à qualificação dos trabalhadores, maior rendimento profissional e garantia de qualidade da assistência. Entretanto, é necessário superar um paradigma de educação continuada nos serviços, que se vale tão somente das oportunidades que surgem para a realização de atividades. Temos que a significar não só como um processo contínuo de aperfeiçoamento, mas com uma forma de ligação com o contexto do trabalho e com as necessidades locais, sem fórmulas prontas ${ }^{(20)}$.

É preciso valorizar também a participação dos enfermeiros como educadores, principalmente em meio às práticas de vigilância em saúde do trabalhador. Contudo, a educação em saúde deve ser caracterizada por propostas de mudanças, desde as atividades nas instituições de ensino, visualizando a política da saúde do trabalhador na formação do enfermeiro e demais elementos da equipe de Enfermagem(15).

\section{CONCLUSÃO}

Uma das formas de impedir o AT é conhecer e controlar os riscos. Neste trabalho, verificou-se que os 
trabalhadores de Enfermagem das USF de João Pessoa possuem adequada percepção (conceitualmente correta e percebida objetivamente) sobre saúde do trabalhador e AT, mas, ainda assim, submetem-se a condições de trabalho insalubres, com sobrecarga de trabalho, falta de infraestrutura e de EPIs em quantidade adequada para uso. Com isso, poderão se expor aos riscos ocupacionais sem a devida proteção, acidentarem-se e, atém mesmo, não notificarem o AT quando o mesmo ocorrer. Torna-se então necessário que a política de atenção à saúde do trabalhador tenha uma aplicação e execução mais enfática para todos os trabalhadores da saúde. Neste sentido sugere-se que os gestores em saúde programem estratégias para melhorar as condições de trabalho e de segurança no trabalho, não só aquelas asseguradas pela

\section{REFERÊNCIAS}

1. Secretaria de Atenção à Saúde, Ministério da Saúde. Departamento de Ações Programáticas Estratégicas. Notificação de acidentes do trabalho fatais, graves e com crianças e adolescentes. Brasília (Brasil): Ministério da Saúde, 2006.

2. Ribeiro PC, Ribeiro ACC, Lima FPBJ. Perfil dos acidentes de trabalho em um hospital de Teresina, PI. Cogitare Enferm. 2010;15(1):110-6.

3. Santos, APB, Novas MMV, Paizante GO. Acidentes de trabalho e biossegurança no ambiente hospitalar. Rev. Edu. Meio Ambiente e Saúde. 2008;1(3):51-62.

4. Secretaria de Políticas de Previdência Social, Departamento do Regime Geral de Previdência Social, Ministério da Previdência Social. Anuário Estatístico da Previdência Social. Capítulo 30 - Acidentes de trabalho. Brasília (Brasil): Ministério da Previdência Social, 2009.

5. Marques D, Silva EM. A enfermagem e o programa saúde da família: uma parceria de sucesso? Rev Bras Enferm. 2004;57(5):545-50.

6. Mauro MYC, Guimarães RM, Mauro CCC. Riscos ocupacionais em saúde. Rev Enferm UERJ. 2004;12:338-45.

7. Chiodi MB, Marziale MHP, Robazzi MLCC. Acidentes de trabalho com material biológico entre trabalhadores de unidades de saúde pública. Rev Latino-am. Enfermagem. 2007; 4(15):123-9.

8. Pinto ESG, Menezes RMP, Villa TCS. Situação de trabalho dos profissionais da Estratégia Saúde da Família em Ceará-Mirim. Rev. esc. enferm. USP. 2010;44(3):657-64.

9. Nunes MBG, Robazzi MLCC, Terra FS, Mauro MYC, Zeitoune RCG, Secco IAO. Riscos ocupacionais dos enfermeiros atuantes na atenção à saúde da família. Rev. enferm. UERJ, 2010;18(2):204-9.

10. Minayo MCS. O desafio do conhecimento: pesquisa qualitativa em saúde. 11 ed. São Paulo: Hucitec-Abrasco, 2008. 11. Comissão de Ética em Pesquisa, Conselho Nacional de Saúde, Ministério da Saúde. Resolução 196/96. Dispõe sobre pesquisas envolvendo seres humanos. Brasília (Brasil); 1996. 12. Cespedes LD, Sarquis MM, Scussiato LA, Miranda FMA, Stein AVJ. Estudo da adesão de trabalhadores com acidentes de trabalho notificados. Cogitare enferm. 2010;15(2):245-9. 13. Galoni T, Robazzi MLCC, Marziale MHP. Acidentes de trabalho com material biológico em hospital universitário de estrutura organizacional e que envolvam a equipe de Enfermagem, mas também aquelas pautadas na mudança de comportamentos oportunizada pela educação permanente em saúde.

Novos estudos sobre a temática precisam ser realizados e aprofundados para termos uma real noção da magnitude do problema, a partir de diferentes setores da Atenção Primária à Saúde, bem como dos diferentes grupos profissionais que neles inserem-se.

\section{AGRADECIMENTOS}

À Profa. Dra. Vera Lúcia do Amaral e Silva (In Memoriam) por suas contribuições na construção final do artigo e por todos os ensinamentos em saúde do trabalhador.

São Paulo. Rev Eletr Enf [Internet]. 2008; 10(3):673-85. Available from: http://www.fen.ufg.br/revista/v10/n3/v10n3a13.htm. 14. Ritter RS, Stumm EMF, Kircher RM. Análise de Burnout em profissionais de uma unidade de emergência de um hospital geral. Rev.Eletr Enf [Internet]. 2009; 11(2):236-48. Available from: http://www.fen.ufg.br/revista/v11/n2/v11n2a02.htm. 15. Simão SAF, Souza V, Borges RAA, Soares CRG, Cortez EA. Fatores associados aos acidentes biológicos entre profissionais de Enfermagem. Cogitare Enferm 2010;15(1):87-91.

16. Spagnuolo RS, Baldo RCS, Guerrini IA. Análise epidemiológica dos acidentes com material biológico registrados no Centro de Referência em Saúde do Trabalhador Londrina/PR Rev Bras Epidemiol. 2008;11(2):315-23.

17. Bonini AM, Zeviani CP, Canini SRMS. Exposição ocupacional dos profissionais de enfermagem de uma unidade de terapia intensiva a material biológico. Rev Eletr Enf [Internet]. 2009; 11(3): 658-64. Available from:

http://www.fen.ufg.br/revista/v11/n3/v11n3a25.htm

18. Izidoro JS, Iwamoto HH, Camargo FC. Delineamento dos acidentes de trabalho em instituições de saúde de uma microrregião de minas gerais. Cogitare Enferm 2010;15(3): 5217.

19. Girondi JBR, Backes MTS, Argenta MI, Meirelles BHS, Santos SMA. Risco, vulnerabilidade e incapacidade: reflexões com um grupo de enfermeiras. Rev Eletr Enf [Internet]. 2010; 12(1):20-7. Available from:

http://www.fen.ufg.br/revista/v12/n1/v12n1a03.htm. 20. Guimarães RM, Mauro MYC, Mendes R, Melo AO, Costa TF. Fatores ergonômicos de risco e de proteção contra acidentes de trabalho: um estudo caso-controle. Rev Bras Epidemiol. 2005;8(3):282-94.

21. Conselho Nacional de Saúde, Ministério da Saúde. Portaria $N^{\circ} 2728 / 2009$. Dispõe sobre a Rede Nacional de atenção Integral à Saúde do Trabalhador (RENAST) e dá outras providências. Brasília (Brasil): Ministério da Saúde; 2009. 22. Conselho Nacional de Saúde, Ministério da Saúde. Portaria No 104/2011. Define as terminologias adotadas em legislação nacional, conforme o disposto no Regulamento Sanitário Internacional 2005 (RSI 2005), a relação de doenças, agravos e eventos em saúde pública de notificação compulsória em todo o território nacional e estabelece fluxo, critérios,

responsabilidades e atribuições aos profissionais e serviços de saúde. Brasília (Brasil): Ministério da Saúde; 2011. 
23. Ribeiro AS, Gabatz RIB, Neves ET, Padoin SMM.

Caracterização de acidente com material perfurocortante e a percepção da equipe de Enfermagem. Cogitare Enferm 2009;14(4):66-6

24. Conselho Nacional de Saúde, Ministério da Saúde. Portaria $\mathrm{N}^{\circ} 485 / 2005$. Aprova a Norma Regulamentadora n. ${ }^{\circ} 32$

(Segurança e Saúde no Trabalho em Estabelecimentos de Saúde). Brasília (Brasil): Ministério da Saúde; 2005.

Artigo recebido em 18/07/2011.

Aprovado para publicação em 08/05/2012.

Artigo publicado em 31/03/2013. 